\title{
Important Success Aspects for Total Quality Management in Software Development
}

\author{
Eman A. Alhazmi \\ Department of Information \\ System, \\ Faculty of Computer and \\ Information Technology, \\ King Abdulaziz University
}

\author{
Walaa A. Bajunaid \\ Department of Information \\ System, \\ Faculty of Computer and \\ Information Technology, \\ King Abdulaziz University
}

\author{
Azrilah Abdul Aziz, PhD \\ Department of Information \\ System, \\ Faculty of Computer and \\ Information Technology, \\ King Abdulaziz University
}

\begin{abstract}
Quality is a fundamental component in the development of software. Consequently, various practitioners and researchers have attempted integrating Total Quality Managements (TQM) concepts in software engineering. Total Quality Data Management (TQDM) refers to a management tactic to longterm achievement through the fulfilment of the needs of clients. According to procedures of (TQDM), data should be managed the same way as products, though guidelines, principles, and methods of TQM for tangible products face various limitations in Total Data Quality Management practices due to the data's nature. This paper discusses significant success factors for quality management and the importance of total quality management in software engineering.
\end{abstract}

\section{Keywords}

Total quality management (TQM), total data quality management (TDQM), continuous improvement.

\section{INTRODUCTION}

Total Quality Management (TQM) refers to a management method to long-term attainment through the gratification of the needs of customers. In a TQM effort, the organizational members take part in enhancing processes, products, services as well as the culture that they work in. TQM is also referred to as total productive maintenance [1]. Besides, it is defined as the method for constant enhancement of the production of products administration and workers. TQM is an integration of administration and quality instruments that are mainly aimed at increasing business as well as minimizing losses that result from the use of inefficient practices.

During the initial years of the computer industry, the key cost of information systems included those incurred in the purchase of hardware. Nonetheless, with the advancement of the software in the few decades, they have become the greater part of the cost equation [2]. The potential of TQM in the arena of software development has recently been acknowledged. Apparently, there are three major concepts that show the relevance as well as the importance of total quality management in the software engineering including quality dimensions, quality evolution, and quality management [3].

The information technology for TQM is currently implemented in most companies. With the introduction of IT in total quality management, many companies have been able to offer their customers with better services and products. With the advent of globalization, the competition at the global level has enhanced the importance of quality in business though it has also added pressure to organizations [1]. These pressures and challenges have led to the renewal on value enhancement for long-term existence of the organization in their industries in which they operate. Essentially, technology serves as an enabling mechanism, which contributes to the enrichment of jobs along with increased job satisfaction.

Top quality management is a management philosophy as well as an asset aimed at enhancing customer-centric practices for conveying quality. The principles of TQM, techniques and practices can be used in all tasks in organizations such as marketing, data systems, finance, and R\&D. The impacts of information technology on the performance of businesses have been studied and reported by various studies. Similarly, many studies have also investigated the effects of TQM on the performance of business. For instance, Yamada et al (2016) claims that management inventions including Total Quality Management immensely depend on IT, which serves as a response mechanism that enables communication and the application of cutting-edge systems, instruments, and modeling methods[4]. Numerous surveys have investigated how particular IT applications affect TQM, and they recommend that essentially, information systems should be highly efficient. For example, to ensure that various needs of customers are satisfied, information regarding their requirements, preference, and desires must be available [5].

Total quality management initially originated from the manufacturing industry though other organizational types including hotel management, churches, and institutions such as schools and universities have adopted it. The software industry is not different from the other industries that were initially using total quality management. Considering that most of the processes of developing software are not perfect, the TQM has been integrated in their development processes. Given that the quality of software cannot be tested, the TQM is used for such functions by interviewing clients or end users.

\section{ISSUE STATEMENT}

TQM concept indicates a critical transformation in the definition as well as treatment of quality in the development of products or services. Under the concept, the customer determines the judgment, and definition of quality. Consequently, the TQM concept acknowledges the existence of a customer-motivated economy. The ideology concentrates on a constant process of enhancement to enable achieving high- value services and products. Gains in productivity are attained through quality improvements [6]. In order to increase the likelihood of success, the implementation of TQM should begin from the topmost administration then downward to the lower administration levels and employees with the aim of benefiting a critical mass of workers. 
According to the concept of total data management (TDQM), organizations ought to manage data as they manage products. However, plans, codes, and methods of TQM for tangible products face various limitations in TDQM activities due to the nature of data. Typically, the life cycle of the data process is classified into three major stages including the design, manufacturing, and application phases. Conferring this model, problems associated with quality are identified and fixed in the point that they emerge at first as well as evaded complications in the succeeding operation.

\section{STUDY OBJECTIVE}

The survey will delve the various strategies as well as issues linked to total quality management challenges, and the various techniques that can be employed in overcoming the problems. The literature review will be based on the findings of 15 research papers.

\section{LITERATURE REVIEW}

April et al., (2012) highlights that in software engineering; the focus is always on problem solving. After the initial creation of the software is completed, continuous improvement is necessary that ensure that the software fully suits the needs of clients as well as an organization. This constant improvement entails examining systems to proactively recognize various opportunities of improvements. In addition, problems associated with the software can be addressed through the improvement methodology [7]. TQM offers the framework to formalize the various steps involved. The steps for continuous development include describing issues, determining the cause, resolving the issues, and follow up, respectively.

The step for describing issues involves two major parts including identification of the issue followed by describing the issue. Various sources can be used in identifying the opportunities of software improvement including ideas collected from trouble reports, employee ideas, and customer complaints. Determining the Cause, which is the second stage, is quite important considering that it assists in getting the root of the problem or the identified opportunities [8]. This phase ensures that the problem is resolved fully. In most cases, symptoms are addressed. The third phase entails resolving the issue and often involves brainstorming or research. Impacts on customers cost and schedules are analyzed at this stage to assist in selecting the most appropriate action. The last step is follow up, which ensures that the changes have been implemented properly and the aspired results have been achieved. Follow up is a continuous process that allows organizations in showing access and demonstrating the effects of the improvements [9].

Calabrese, Armando, and Michele Corbo (2015) realize the association between TQM application scope and the performance of businesses, as well as the impact of the support of co-worker and the support of business on the total quality management versus relationship of performance [10]. There is an increasing recognition of the role played by the aspects of humans in management of quality in the viewpoint of common total quality management application. The major characteristics of TQM organization includes teamwork, communication between a company and its clients, administration, employee authorization and contribution, the feedback of customers, and management of trust and support [11]

Obeidat, Bader Yousef, et al. (2016) contends that human resources are vital for the success of TQM. Hence, it can be assumed that the awareness of people regarding quality is core to the goal of TQM. For that reason, the main argument of the article includes the fact that even though the TQM acronyms, as well as several of its theories and practices, are well recognized by the assessors, the actual consciousness of the indulgent side of the TQM concept is usually very shallow and most individuals have a relatively inadequate knowledge of it [12]. Khanam, et al. (2013) suggested a research that experiences how structuring and application of TQM should be done in a TQM setting as well as the participation benefits the achievement of positive outcomes. It is worth acknowledging that the immerse participation in organizations and integration of quality management and its implementation with the commitment and involvement of all the members [13]. Mitchell (2013) suggested that exists three major notions that explain the significance and relevance of TQM in software engineering; these concepts include quality evolution, management, and dimensions [14].

A key element of the total quality management is the individuals involved to run and manage the software effectively without any crush or hacks. From the software engineering perspective, this aspect comprises of the end users and the designers of software. The designers are considered the implementers of the total quality management along with software engineering integration. Notably, the developers should be well trained to enable the production of standard software as well as monitor the development process of the software while concentrating on the total quality. Sinha et al., (2016) report concentrates on the various problems encountered by the 5ESS along with how TQM can be applied in overcoming these issues. This paper recapitulates the slant, contemporary status, and approximately early fallouts of our determinations to intellectualize, design, and accomplish a quality management coordination of the 5ESS. The 5ESS includes a 5-class electronic switch system of telephone that was designed as well as developed by the AT\&T telephone company. The system was intended to be a digital exchange to satisfy the desires of administrators of telecommunication making conversion to digital from analog exchanges [1]. The total quality management highlights the method for improving quality, reduce the interval between the delivery of products and development, maximize revenues, and minimize costs. Theoretically, total quality management is a technique of management that is designed to change the needs of the clients into satisfaction and organization success [15]

Rai et al., (2015) revealed that TQM concentration is among the vital requirements in a telecommunication industry that is experiencing stiff competition. The report explains how companies' noteworthy development towards TQM can be attained during the lifecycle of the development of software through the application of an inclusive program of preventing defects. The outcomes of the initiative included heightened productivity, more satisfaction of customers, and greater quality products. Various techniques can be applied in the development of cultural frameworks for total quality management including attaining TQM through the defect prevention approach. This model is a fundamental model in the process of preventing defects that can be applied to almost any stage during the development of software. This approach comprises of four major activities that are assimilated into the development phase including an action team, meetings for causal analysis, and a kick off meeting, tracking systems and data collection [2].

John et al., (2016) research explains some of the methods that can be used in the identification of issues associated with the organization of software development. Essentially, the 
methods include a continuous improvement approaches that consist conducting satisfaction studies that are performed face to face with the customers. Such an approach is targeted at recognizing weaknesses and strengths and addressing the various issued that may be identified. The article covers the experiences of the authors with total quality management because of its introduction in the organization of software development leading to the long history of the application of the IS09001 quality systems [3].

\section{IMPLEMENTATION}

Papadopoulos \& Georgios (2015) proposes that TDQM should be monitors in the same way that products are monitored. However, guidelines, principles, and techniques of TQM for tangible products have various limitations in total development quality management due to the nature of the data. The lifecycle of data is usually categorized into three major stages including the designing, manufacturing, and application phases. Rendering this model, problems associated with quality are solved in the stage in which they emerge and complications are avoided in the next operations. TDQM engineering is quite expensive. Nonetheless, the data specialists anticipate that data management does not affect their activities [5].

\section{ANALYSIS}

From the 15 papers used in the literature review, the study was able to extract vital factors of success of total quality management. The two charts below sort the various critical vital aspects in accordance with their occurrence frequencies. The charts show the frequency of occurrence and the percentage frequency of occurrence of the "vital few "of the critical success factors extracted from the 15 papers used in the study. As shown in the charts, Quality system and performance, dominate in the vital few of critical success for quality managements in software development. Apparently, $80 \%$ of the complaint types arise from $20 \%$ of the complaint types (Quality system and performance QSP) meaning that they can be integral in the organizational and operational performance.

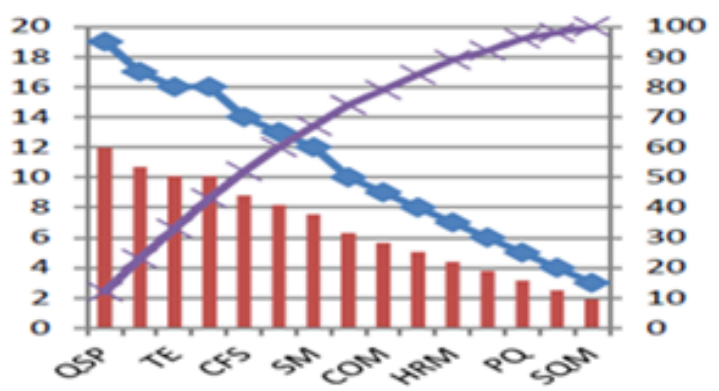

Percentage frequency of occurrences

Frequency of occurrences

Cumulative Percentage

Figure 1: Pareto analysis chart of TQM CSFs [6]

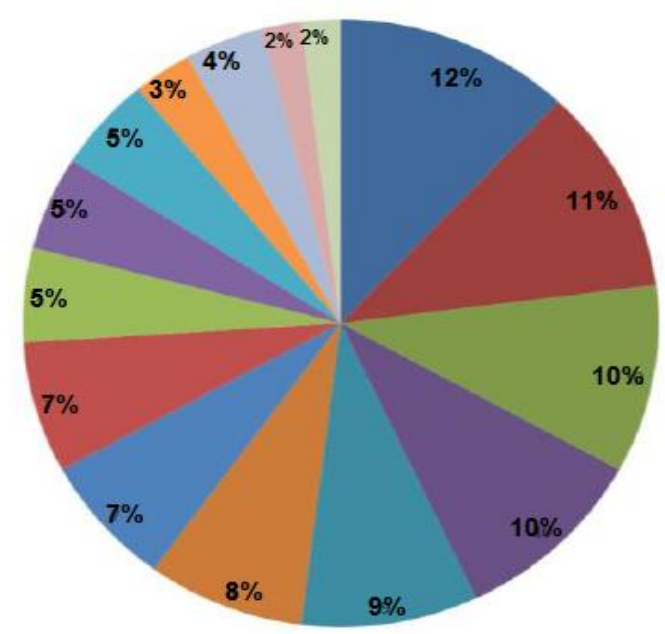

Quality systems and performance

Top management commitment

Training and education

Continuous improvement and customer emphasis

Customer satisfaction and focus

Quality information and measurement of performance

Supplier management

Employee authorization

Communication

Process management

Human resource management

Quality assurance

Product quality

TDQM

Strategy quality management

Figure 2: Pareto analysis chart of TQM CSFs [6]

The charts show the frequency of occurrence and the percentage frequency of occurrence of the "vital few "of the critical success factors extracted from the 15 papers used in the study. As shown in the charts, Quality system and performance, dominate in the vital few of critical success for quality managements in software development. Apparently, around $80 \%$ of the complaint types arise from $20 \%$ of the complaint types (Quality system and performance QSP) meaning that they can be integral in the organizational and operational performance.

An integration of the Total Quality Management principles into the development cycle of software applications is founded on the underlying need to enhance product quality, accelerate schedules, and minimize the involved costs of development and maintenance, according to Samson and Terziovski (1999) [16]. Therefore, TQM will have a farreaching significance to the design and development of the application in that it will improve understandability, reliability, visibility, application robustness, supportability, and maintainability. Among the primary approached that TQM will incorporate into the software development cycle to improve the applications' quality will include performance measure of the software, analysis of the expected functionalities of the system, and possibly making changes whenever necessary to ensure that the system meets its basic requirements and efficiency thresholds [17]. For instance, the first stage of process measurement in TQM involves assessing the attributes of the process based on the application's 
baseline improvement requirements. The second stage of process analysis involves scrutinizing the entire software development stages to identify possible bottlenecks and development shortfalls. The final stage of change initiation and implementation go in line with the observations made during the analysis stage [18].

\section{CONCLUSION}

As revealed in the above literature review, Quality is a vital element in the software development, and various practitioners and researchers have attempted integrating Total Quality Managements (TQM) concepts in software engineering. An improvement in the quality of the plans, prototypes, and steps taken in the development of any software reflects the reduced costs incurred in completing the entire work since less rework will be involved, no delays in the schedule experienced, and efficiency in the machine and material use realized. Controlled inconveniences during the development cycle also mean that the development team will be noted to have an improved rate of productivity, while the software development organization will enjoy a quick capture of the market following its quality products. Additional benefits that can follow include a longer stay in the business and the creation of more employment opportunities.

TQM initially originated from the manufacturing industry though other organizational types including hotel management, churches, and institutions such as schools and universities have implemented it. The software industry is not different from the other industries that were initially using total quality management. According to the paper's conclusions, top management commitment is among the top CSFs with customer satisfaction and focus. As revealed, the needs of clients are critical in the various stages of software development. TQM can be applied in preventing the challenge of rushing an inferior product or service through the six phases. Based on the investigations of the work leading authors to show the "vital few" critical success factors necessary for the implementation of total quality management for efficient business performances and enhancement in quality service, the Quality system and performance factor dominate in the vital few of critical success for quality managements in software development. Essentially, the vital few critical success factors can be used in organizations and can be linked to both organizational and operational performance. These results can assist managers as well as practitioners for enhanced implementation of total quality management programs in organizations

\section{REFERENCES}

[1] Sinha, N., Garg, A. K., \& Dhall, N. (2016). Effect of TQM principles on performance of Indian SMEs: the case of automotive supply chain. The TQM Journal, 28(3), 338-359.

[2] Rai, Priyanka Vikas, and P. N. Mukherjee. (2015) Impact of TQM Concepts in Automobile Industry as a Strategic Advantage-A Review. Journal of Global Economy 11.4 (2015): 311-324

[3] John, Boby, R. S. Kadadevaramath, and Edinbarough A. Immanuel. (2016). Recent Advances in Software Quality Management.

[4] Yamada, Shigeru, and Yoshinobu Tamura. Software Reliability. (2016) OSS Reliability Measurement and Assessment. Springer International Publishing, 2016. 113.
[5] Papadopoulos \& Georgios. (2015) Moving from Traditional to Agile Software Development Methodologies Also on Large, Distributed Projects. Procedia-Social and Behavioral Sciences 175: 455-463.

[6] Tariq, B., \& Anwar, S. (2015). Implementing Pareto Analysis of Total Quality Management for Service Industries Projects.

[7] April, Alain, and Alain Abran. Software maintenance management: evaluation and continuous improvement. Vol. 67. John Wiley \& Sons, 2012.

[8] Wohlin, Claes, et al. Experimentation in software engineering. Springer Science \& Business Media, 2012.

[9] Unterkalmsteiner, Michael, et al. "Evaluation and measurement of software process improvement-a systematic literature review." IEEE Transactions on Software Engineering 38.2 (2012): 398-424.

[10] Calabrese, Armando, and Michele Corbò. (2015) Design and blueprinting for total quality management implementation in service organizations. Total Quality Management \& Business Excellence 26.7- 8.p 719 732.

[11] Underwood, S. (2016). Exploring Organizations' Software Quality Assurance Strategies.

[12] Obeidat, Bader Yousef, et al. (2016) The Effect of Knowledge Management Uses on Total Quality Management Practices: A Theoretical Perspective. Journal of Management and strategy.

[13] Khanam, S, Siddiqui, J. and Talib, F. (2013), "Role of Information Technology in Total Quality Management: A Literature Review", International Journal of Advanced Research in Computer Engineering and Technology 2.8 (2016): 2433-2445.

[14] Mitchell K. D. Ram, (2013). Total Quality Management in Software Engineering, Department of Management Science and Information Systems, University of Auckland. Published in: Software Education Conference.Proceedings.IEEE conference publication.

[15] Khanam, S., \& Talib, F. (2016, April). Study of TQM Enablers and IT Resources in Indian ICT Organizations. In National Conference on Mechanical EngineeringIdeas, Innovations \& Initiatives.

[16] Samson D. \& Terziovski M. (1999). The relationship between Total Quality Management practices and operational performance. Journal of Operations Management 17(4): 393 - 409.

[17] Parzinger M.J. \& Nath R. (2000). A study of the relationships between total quality management implementation factors and software quality. Total Quality Management 11(3): 353-371

[18] Subramanian G.H., Jiang J.J., \& Klein G. (2007). Software quality and IS project performance improvements from software development process maturity and IS implementation strategies. Journal of Systems and Software 80(4): 616-627. 